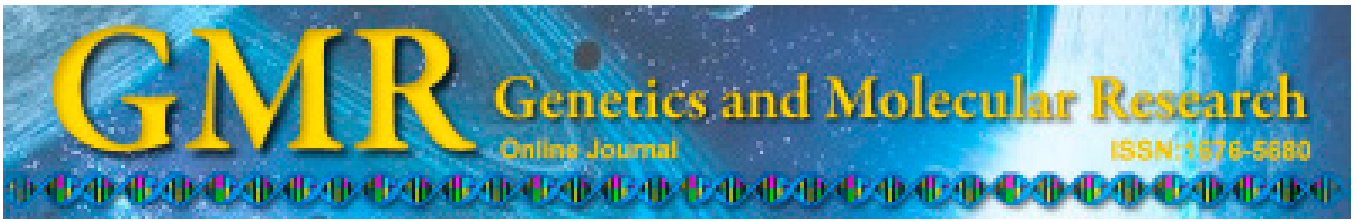

\title{
Antioxidant content and cytological examination of aqueous fluid from patients with age-related cataracts at different stages
}

\author{
X. Wang ${ }^{1}$, J. Sun ${ }^{2}$, G.F. Dang ${ }^{3}$, Y. Gao ${ }^{3}$, L. Duan ${ }^{3}$ and X.Y. Wu ${ }^{1}$ \\ ${ }^{1}$ Department of Ophthalmology, Qilu Hospital, \\ Medical School of Shandong University, Qilu, Shandong, China \\ 2Department of Ophthalmology, People's Hospital of Longkou, \\ Longkou, Shandong, China \\ ${ }^{3}$ Department of Ophthalmology, \\ Shandong Provincial Qian Fo Shan Hospital, Jinan, Shandong, China \\ Corresponding author: X.Y. Wu \\ E-mail: xinyiwu566@163.com
}

Genet. Mol. Res. 14 (2): 6251-6255 (2015)

Received August 20, 2014

Accepted February 6, 2015

Published June 9, 2015

DOI http://dx.doi.org/10.4238/2015.June.9.11

\begin{abstract}
We investigated the antioxidant content and conducted a cytological examination of the aqueous fluid and lenses of patients with age-related cataracts at different stages. The levels of superoxide dismutase (SOD), catalase (CAT), and glutathione peroxidase (GSH$\mathrm{PX}$ ) in the aqueous fluid and lenses were determined by the xanthine oxidase method, the colorimetric method, and the improved reduced glutathione (GSH) depletion method, respectively. SOD, CAT, and GSH-PX content in the aqueous fluid and lenses decreased significantly with increasing lenticular nucleus hardness grading. However, the number of white blood cells, neutrophils, monocytes, lymphocytes, and eosinophils did not vary significantly with varying lenticular nucleus hardness. Antioxidant content examination is an important quantitative indicator for clinical diagnosis and treatment of age-related cataracts. Antioxidant content in the aqueous fluid and lenses decreased
\end{abstract}


significantly with increasing lenticular nucleus hardness grading. Lenses at hardness level V had the lowest content of antioxidants.

Key words: Age-related; Cataracts; Antioxidants; Cytology

\section{INTRODUCTION}

Age-related cataracts is an eye disease caused by multiple factors. It seriously affects visual function and accounts for more blindness than any other eye disease. At present, most researchers generally believe that oxidative damage by free radicals is an important factor for age-related cataracts formation (Choy et al., 2011). Here, we focused on the antioxidant content and the results of a cytological examination of the aqueous humor of age-related cataracts patients at different stages.

\section{MATERIAL AND METHODS}

\section{Materials}

One hundred subjects ( 53 males and 47 females) were enrolled. The mean age of subjects was $68.1 \pm 1.3$ years (51-86 years). All patients were diagnosed with age-related cataracts. Among them, the level of the lenticular nucleus hardness was II in 23 cases, III in 36 cases, IV in 38 cases, and V in 3 cases. No patients had ocular trauma or high myopia history, etc. Aqueous fluid $(0.2 \mathrm{~mL})$ was extracted using a $1-\mathrm{mL}$ syringe and preserved at $4^{\circ} \mathrm{C}$. Intracapsular lens extraction was performed and the lens was washed with phosphate-buffered saline. After drying on filter paper, the lens was ground into a homogenate while cooling using an ice bath. Finally, the homogenate was centrifuged at $10,000 \mathrm{~g}$ for $15 \mathrm{~min}$ and examined after $12 \mathrm{~h}$.

\section{Instruments and equipment}

Superoxide dismutase (SOD), catalase (CAT), and glutathione peroxidase (GSH-PX) kits were bought from Dong Song bo Industry Biotechnology (Beijing, China). An Axiostar Plus microscope was acquired from Zeiss (Oberkochen, Germany).

\section{Methods}

SOD content was determined by the xanthine oxidase method. Homogenate $(0.003$ $\mathrm{mL}$ ) was mixed with $0.1 \mathrm{~mL} \mathrm{H} \mathrm{O}_{2}, 0.1 \mathrm{~mL}$ liquid matrix, $0.1 \mathrm{~mL}$ nitroso agent, and $0.2 \mathrm{~mL}$ enzyme solution, and incubated at $37^{\circ} \mathrm{C}$ for $40 \mathrm{~min}$. The mixture was then added to $2 \mathrm{~mL}$ color developing agent and examined at $550 \mathrm{~nm}$ wavelength. SOD content $=($ absorbance of control tube-absorbance of test tube $) \div$ absorbance of control tube $\div 0.5 \mathrm{x}$ dilution ratio.

GSH-PX content was determined by the improved reduced GSH depletion method. The homogenate $(0.02 \mathrm{~mL})$ was diluted with $1 \mathrm{~mL}$ water and incubated at $37^{\circ} \mathrm{C}$ for $5 \mathrm{~min}$. The solution $(0.4 \mathrm{~mL})$ was added to $4 \mathrm{~mL}$ agent and centrifuged at $3500-4000 \mathrm{rpm}$. The GSH-PX content was detected at $420 \mathrm{~nm}$ and calculated by colorimeter with a $1 \mathrm{~cm}$ optical path. GSH$\mathrm{PX}=\left(\mathrm{OD}\right.$ control $\left.-\mathrm{OD}{ }_{\text {test }}\right) \times \mathrm{A} \times 5 \div 3$ min $\times$ protein weight. $\mathrm{A}=$ standard GSH concentration/ optical density (OD) standard GSH absorbance.

The CAT level was determined by the colorimetric method. Three tubes were used as blanks. In detail, blank 1 contained $1 \mathrm{~mL}$ liquid matrix, $1 \mathrm{~mL}$ ammonium molybdate and $0.2 \mathrm{~mL}$ 
homogenate; blank 2 comprised $1 \mathrm{~mL}$ liquid matrix, $1 \mathrm{~mL}$ ammonium molybdate, $0.2 \mathrm{~mL}$ buffer; and blank 3 included $1.2 \mathrm{~mL}$ buffer and $1 \mathrm{~mL}$ ammonium molybdate. The homogenate $(0.02$ $\mathrm{mL}$ ) was diluted to $1 \mathrm{~mL}$ and incubated at $37^{\circ} \mathrm{C}$ for $1 \mathrm{~min}$ to prepare the test tube. After mixing with $1 \mathrm{~mL}$ liquid matrix, $1 \mathrm{~mL}$ ammonium molybdate was added and the investigation was conducted at $405 \mathrm{~nm}$ after $10 \mathrm{~min}$. CAT $(\mathrm{kU} / \mathrm{L})=\left(\mathrm{OD}_{\text {blank } 1}-\mathrm{OD}_{\text {test }}\right) /\left(\mathrm{OD}_{\text {blank } 2}-\mathrm{OD}_{\text {blank }}\right)$ x 325 .

White blood cells were counted using a counting plate and a Zeiss Axiostar Plus microscope. The aqueous fluid was centrifuged at $1500 \mathrm{rpm}$ for $10 \mathrm{~min}$ and colored for counting.

Lenticular nucleus hardness was mainly determined by slit lamp examination based on color for grading: Level I, the lenticular nucleus was transparent and soft; Level II, the lenticular nucleus presented as white or yellowish-white; Level III, the middle nucleus presented as yellow; Level IV, there was a hard core with an amber nucleus; and Level IV, there was a special hard core with a brown or black nucleus.

\section{Statistical analysis}

Measurement data are reported as means and standard deviation (means $\pm \mathrm{SD}$ ). Differences between groups were analyzed using the F-test or the chi-square test. All statistical analyses were performed using the SPSS19.0 software (Chicago, IL, USA). P values $<0.05$ were considered to be statistically significant.

\section{RESULTS}

SOD, CAT, and GSH-PX content in the aqueous fluid and in lenses of different lenticular nucleus hardness were examined. The content of SOD, CAT, and GSH-PX decreased significantly with increasing lenticular nucleus hardness $(\mathrm{P}<0.05)$ (Table 1$)$.

Table 1. SOD, CAT, and GSH-PX content in aqueous fluid and lenses of varying lenticular nucleus hardness.

\begin{tabular}{lccc}
\hline Lenticular nucleus hardness & SOD $(\mathrm{U} / \mathrm{mL})$ & GSH-PX $(\mathrm{U} / \mathrm{mL})$ & CAT $(\mathrm{U} / \mathrm{mL})$ \\
\hline Level II & $95.46 \pm 11.08$ & $83.62 \pm 22.47$ & $0.18 \pm 0.12$ \\
Level III & $86.72 \pm 13.4$ & $69.36 \pm 21.52$ & $0.11 \pm 0.08$ \\
Level IV & $76.68 \pm 11.21$ & $52.16 \pm 19.10$ & $0.08 \pm 0.12$ \\
Level V & $61.35 \pm 10.30$ & $40.03 \pm 22.18$ & $0.05 \pm 0.03$ \\
F & 6.52 & 5.73 & 6.12 \\
P & $<0.001$ & $<0.01$ & $<0.01$ \\
\hline
\end{tabular}

$\mathrm{P}$ : comparison among groups.

Aqueous fluid cytological examinations were conducted for lenticular nuclei of varying hardness. The number of white blood cells, neutrophils, monocytes, lymphocytes, and eosinophils did not vary significantly with varying lenticular nucleus hardness (Table 2).

\begin{tabular}{|c|c|c|c|c|c|}
\hline $\begin{array}{l}\text { Lenticular nucleus } \\
\text { hardness }\end{array}$ & $\begin{array}{l}\text { Neutrophils } \\
\text { (cell count } / \mu \mathrm{L} \text { ) }\end{array}$ & $\begin{array}{c}\text { Monocytes } \\
(\text { cell count } / \mu \mathrm{L})\end{array}$ & $\begin{array}{l}\text { Lymphocytes } \\
(\text { cell count } / \mu \mathrm{L})\end{array}$ & $\begin{array}{c}\text { Eosinophils } \\
(\text { cell count } / \mu \mathrm{L})\end{array}$ & $\begin{array}{l}\text { White blood cells } \\
(\text { cell count } / \mu \mathrm{L})\end{array}$ \\
\hline Level II & $8.1 \pm 2.2$ & $5.1 \pm 1.7$ & $0.3 \pm 0.1$ & $3.5 \pm 2.0$ & $50.2 \pm 11.2$ \\
\hline Level III & $8.5 \pm 3.1$ & $5.5 \pm 1.2$ & $0.2 \pm 0.1$ & $3.1 \pm 2.1$ & $53.1 \pm 13.1$ \\
\hline Level IV & $8.8 \pm 2.5$ & $4.9 \pm 1.8$ & $0.1 \pm 0.1$ & $3.3 \pm 2.6$ & $52.2 \pm 11.6$ \\
\hline Level V & $8.1 \pm 2.9$ & $5.2 \pm 1.3$ & $0.3 \pm 0.2$ & $3.2 \pm 2.3$ & $51.5 \pm 10.8$ \\
\hline $\mathrm{F}$ & 0.22 & 1.40 & 1.20 & 1.35 & 1.56 \\
\hline $\mathrm{P}$ & $>0.12$ & $>0.07$ & $>0.07$ & $>0.07$ & $>0.12$ \\
\hline
\end{tabular}

$\mathrm{P}$ : comparison among groups. 


\section{DISCUSSION}

Cataracts have become a hot topic for society following medical developments and the general extension of human longevity (Esfandiari et al., 2008; Hafizuddin et al., 2011).

$\mathrm{Li}$ and Spector (1996) proposed that oxidative damage is the active factor in the formation of cataracts. GSH is reduced while mixed disulfide comprising GSSG and protein increases in lenses following oxidative damage (Frankel and Berenbaum, 2006; Hosu et al., 2011a). A series of changes in elderly patients' lenses appeared, such as pigmentation, reduced transparency, and protein structure change, all of which make the lens more susceptible to oxidative damage (Rautenbach et al., 2010; Hosu et al., 2011).

SOD is an important antioxidant enzyme in the body (Esfandiari et al., 2008). SOD, GSH-PX, and CAT decreased in the aqueous fluid and lenses of the patients with age-related cataracts with increasing hardness of the lens nucleus. Large amounts of reactive oxygen species accumulate in the aqueous fluid and lenses with age; they cause SOD and GSH-PX consumption, changing the soluble proteins in the lens into insoluble proteins, which results in lens opacity (Lu and Rasco, 2012; Gupta and Ahmad, 2013). Reduced CAT weakens the antioxidant capacity of the lens epithelial cells and induces their apoptosis, which also causes cataracts (Ravipati et al., 2012; Zhu et al., 2013).

A lack of significant changes in the number of white blood cell, neutrophils, monocytes, lymphocytes, and eosinophils with varying lenticular nucleus hardness indicates that age-related cataracts have no relationship to eye inflammation (Croft et al., 1995; Sakr and El-Metwally, 2009).

In conclusion, aqueous fluid antioxidant content detection is an important quantitative indicator for the clinical diagnosis and treatment of age-related cataracts. Aqueous fluid antioxidants decrease significantly with increasing lenticular nucleus hardness, and reach a minimum at hardness Level $\mathrm{V}$, at which point an ultrasonic emulsification operation is unsuitable (Bonaccio et al., 2013; Zhu et al., 2013).

\section{REFERENCES}

Bonaccio M, Di Castelnuovo A, Bonanni A, Costanzo S, et al. (2013). Adherence to a Mediterranean diet is associated with a better health-related quality of life: a possible role of high dietary antioxidant content. BMJ Open 3: e003003.

Choy CK, Cho P and Benzie IF (2011). Antioxidant content and ultraviolet absorption characteristics of human tears. Optom. Vis. Sci. 88: 507-511.

Croft KD, Williams P, Dimmitt S, Abu-Amsha R, et al. (1995). Oxidation of low-density lipoproteins: effect of antioxidant content, fatty acid composition and intrinsic phospholipase activity on susceptibility to metal ion-induced oxidation. Biochim. Biophys. Acta 1254: 250-256.

Esfandiari E, Shakiba MR, Mahboob SA, Alyari H, et al. (2008). The effect of water stress on the antioxidant content, protective enzyme activities, proline content and lipid peroxidation in wheat seedling. Pak. J. Biol. Sci. 11: 19161922.

Frankel S and Berenbaum M (2006). Effects of light regime on antioxidant content of foliage in a tropical forest community. Biotropica 31: 422-429.

Gupta AK and Ahmad M (2013). Effect of refinery waste effluent on tocopherol, carotenoid, phenolics and other antioxidants content in Allium cepa. Toxicol. Ind. Health 29: 652-661.

Hafizuddin M, Ghani A and Ahmad S (2011). The comparison of water absorption analysis between counterrotating and corotating twin-screw extruders with different antioxidants content in wood plastic composites. Adv. Mater. Sci. Eng. 2011: Article ID 406284.

Hosu AD, Cimpoiu C, Miclauş V and Jäntschi L (2011a). Antioxidant content of three different varieties of wine grapes. Biotechnol. Biotechnol. Equipment 25: 2217-2221. 
Hosu AD, Cimpoiu C, Pop N, Miclauş V, et al. (2011b). The analysis of different factors affecting the red wines antioxidant content. Notulae Botanicae Horti Agrobotanici Cluj-Napoca 39: 159-164.

Li WC and Spector A (1996). Lens epithelial cell apoptosis is an early event in the development of UVB-induced cataract. Free Radic Biol. Med. 20: 301-311.

Lu X and Rasco BA (2012). Determination of antioxidant content and antioxidant activity in foods using infrared spectroscopy and chemometrics: a review. Crit. Rev. Food Sci. Nutr. 52: 853-875.

Rautenbach F, Faber M, Laurie S, Laurie R, et al. (2010). Antioxidant capacity and antioxidant content in roots of 4 sweetpotato varieties. J. Food Sci. 75: C400-C405.

Ravipati AS, Zhang L, Koyyalamudi SR, Jeong SC, et al. (2012). Antioxidant and anti-inflammatory activities of selected Chinese medicinal plants and their relation with antioxidant content. BMC Complement. Altern. Med. 12: 173.

Sakr MT and El-Metwally MA (2009). Alleviation of the harmful effects of soil salt stress on growth, yield and endogenous antioxidant content of wheat plant by application of antioxidants. Pak. J. Biol. Sci. 12: 624-630.

Zhu C, Sanahuja G, Yuan D, Farré G, et al. (2013). Biofortification of plants with altered antioxidant content and composition: genetic engineering strategies. Plant Biotechnol. J. 11: 129-141. 